\title{
Currículo de ciências dos três primeiros anos do ensino fundamental: o uso de livros de literatura infantil
}

\author{
Science curriculum of the first three years of elementar school: the use of \\ children's literature books
}

Lívia da Silva Queiroz ${ }^{1}$; Maria Margarida Gomes ${ }^{2}$

\begin{abstract}
Resumo
Este estudo tem como finalidade compreender que normas e padrões regulam o currículo de Ciências dos três anos iniciais do ensino fundamental a partir do uso de livros de literatura infantil. Entende-se o currículo como construído social e historicamente em decorrência de disputas no interior de comunidades disciplinares, resultando na valorização de certas formas de saber. Concebe-se os livros como objetos escolares que carregam vestígios da cultura escolar. Metodologicamente, analisa-se transcrições de entrevistas realizadas com quatro professoras e livros de literatura infantil. Os resultados vêm indicando que o uso desses objetos se articula a práticas subversivas, revelando o caráter inventivo da atuação docente para articular textos literários e o currículo de Ciências.
\end{abstract}

Palavras-chave: Currículo; Materiais didáticos; Cultura material; Ensino de Ciências; Literatura infantil.

\begin{abstract}
This study aims to understand which norms and standards regulate the science curriculum of the first three years of elementary school using children's literature books. The curriculum is understood as socially and historically constructed due to disputes in disciplinary communities, which result in the valuation of certain forms of knowledge. Books are conceived as school objects that carry traces of school culture. Methodologically, four teachers' interviews and two children's literature books are analyzed. The results have indicated that the use of these objects is linked to subversive practices, revealing the inventive nature of teaching activities to articulate literary texts and the Science curriculum.
\end{abstract}

Keywords: Curriculum; School objects; Material culture; Science teaching; Children's literature.

\footnotetext{
${ }^{1}$ Doutoranda em Educação - Universidade Federal do Rio de Janeiro (UFRJ). Rio de Janeiro, RJ - Brasil. Email: liviaqueiroz12@yahoo.com.br

${ }^{2}$ Doutora em Educação - Universidade Federal Fluminense (UFF). Niterói, RJ - Brasil. Professora Associada Universidade Federal do Rio de Janeiro (UFRJ). Rio de Janeiro, RJ - Brasil. E-mail: margaridaplgomes@gmail.com
}

Submetido em: 09/04/2020 - Aceito em: 14/06/2020 


\section{Introdução}

Neste texto buscamos refletir sobre aspectos que regulam conhecimentos escolares no currículo de Ciências dos três anos iniciais do Ensino Fundamental (EF), adotando como objeto de análise o uso de livros literários com fins didáticos. Tendo como principal finalidade compreender as ideias que regulam o currículo a partir do uso de livros de literatura infantil em aulas de Ciências, e práticas docentes articuladas a eles, analisamos dois livros literários: $O$ diário de uma minhoca, de Doreen Cronin, e Cocô de Passarinho, de Eva Furnari.

Assim, este trabalho é parte de uma proposta mais ampla, cujo principal objetivo é analisar o uso, com fins didáticos, de dez livros de literatura infantil em aulas de Ciências. Os livros tratados foram selecionados por quatro docentes entrevistadas na pesquisa realizada por Queiroz (2019) $)^{3}$. Aqui, nos referimos a dois dos dez livros indicados por essas professoras.

Ao discorrer sobre o currículo de Ciências dos três primeiros anos do EF através do uso de materialidades e objetos, Queiroz (2019) notou uma quantidade significativa de materiais e recursos que são mobilizados em aulas de Ciências de colégios universitários no Rio de Janeiro $^{4}$. Embora seja notória a variedade no conjunto de materiais utilizados pelas docentes, nesses colégios é perceptível a predominância de livros de literatura infantil (QUEIROZ, 2019). Esse fato indica a presença marcante dos textos literários na construção do currículo de Ciências.

Sendo assim, o estudo suscitou questões acerca do trabalho docente e da construção de conhecimentos escolares de Ciências a partir do uso de livros de literatura infantil. De que modo um texto literário, que não se pretende, a priori, atender às demandas escolares, é (res)significado no currículo de Ciências? Quais intenções pedagógicas se articulam a ele? Como se dá a mediação entre o livro de literatura e o currículo de Ciências? Instigadas por tais questões, temos nos debruçado sobre livros de literatura infantil utilizados em aulas de Ciências.

Contudo, é pertinente ressaltar que, embora não seja a finalidade dessas obras, os livros de literatura infantil aparecem como um potente recurso de ensino de Ciências em turmas de alfabetização, e, por vezes, em contextos escolares, esse recurso tem incorporado significados e finalidades didáticas (LOPES; SALOMÃO, 2009).

\footnotetext{
${ }^{3}$ Os dados fazem parte da dissertação de mestrado intitulada Currículo de Ciências nos anos iniciais do ensino fundamental: materiais didáticos utilizados em colégios universitários do Rio de Janeiro (PPGE/UFRJ), que teve como principal finalidade compreender, através dos usos de objetos materiais, quais regulações constituem e asseguram a inserção de conhecimentos da disciplina Ciências no currículo dos três anos iniciais do EF.

${ }^{4}$ Colégio de Aplicação da Universidade Federal do Rio de Janeiro (CAp/UFRJ) e Colégio Universitário Geraldo Reis da Universidade Federal Fluminense (Coluni/UFF).
} 
DOI: https://doi.org/10.46667/renbio.v13i1.306

Assim, é no âmbito de anos escolares nos quais, histórica e tradicionalmente, livros de literatura infantil vêm sendo concebidos como necessários (LAJOLO; ZILBERMAN, 2007), que objetivamos compreender quais normas e padrões (POPKEWITZ, 2011, 2014) regulam o currículo dos três anos iniciais do EF, através do uso de livros de literatura infantil com fins didáticos em aulas de Ciências. Tal finalidade foi elaborada em diálogo, principalmente, com os pressupostos teóricos de Ivor Goodson (1997, 2013), que nos atentam para as dinâmicas sociais e históricas imbricadas na construção do currículo escolar, por meio de disputas por status e conhecimentos que ocupam lugar no currículo. Tais embates são protagonizados por comunidades disciplinares que atuam mais ativamente na construção do currículo, sendo responsáveis pela seleção e organização dos conhecimentos.

Aproximando-nos de estudos que buscam pensar o currículo discursivamente, consideramos a produção de Thomas Popkewitz $(2011,2014)$ no olhar que projetamos sobre este artefato. Portanto, percebemos que, em decorrência das disputas das comunidades disciplinares (GOODSON, 1997, 2013), o currículo legitima certos padrões de comportamento e formas de raciocínio. Assim, o currículo e as matérias escolares estão imbricados a questões de poder, inerentes aos conhecimentos que ocupam espaço no currículo escolar. Isso ocorre devido à organização do conhecimento escolar, que favorece a corporificação de modos de ser, pensar e agir, e "ver" o mundo e o "eu” (POPKEWITZ, 2011).

No que tange ao uso de livros de literatura infantil com fins didáticos, concebemos tais recursos como objetos escolares historicizados que carregam signos e sinais que permitem acessar a cultura e a forma escolar (BENITO, 2010; 2017). Pontuamos que buscamos não reduzir a análise dos objetos às finalidades de produção, mas, em contraponto, visibilizar as subversões e aspectos inventivos atribuídos por seus usuários (VIDAL, 2005).

Para o melhor entendimento, o texto se divide em três partes, além desta introdução. $\mathrm{Na}$ próxima seção, apresentamos os referenciais teórico-metodológicos que constroem nosso olhar sobre o currículo, materiais didáticos e livros de literatura infantil e a metodologia adotada. Em seguida, analisamos os livros e as práticas articuladas ao seu uso. E, por fim, tecemos considerações acerca da discussão proposta.

\section{Abordagem teórico-metodológica}

\subsection{Currículo de Ciências, materiais didáticos e objetos escolares}

Com base no arcabouço teórico que adotamos, argumentamos que o currículo escolar de Ciências se constitui em meio a aspectos históricos e sociais. Sua organização ocorre em decorrência de disputas de grupos e subgrupos no interior de comunidades profissionais que se articulam em torno de sua construção (GOODSON, 1997, 2013). Nesse sentido, o currículo não se constitui em um objeto estático e desinteressado. Em contraponto, é passível de mudanças e transformações e, como resultado dos conflitos que perpassam sua construção, carrega sentidos e privilegia determinadas formas de raciocínio. 
Deste modo, em diálogo com as ideias de Thomas Popkewitz (2011), percebemos a importância de se historicizar o processo de escolarização em investigações do campo do currículo, a fim de produzir um estudo que esteja centrado nas questões históricas inerentes aos conhecimentos. Em outras palavras, conceber o currículo como produto da história implica em percebê-lo...

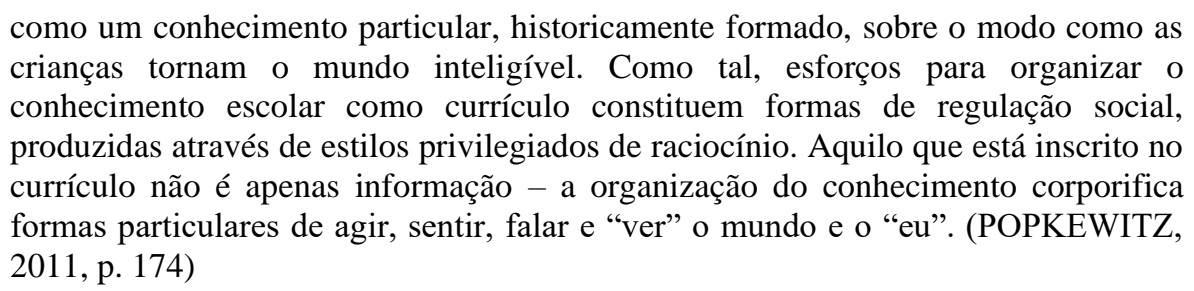

Assim, operamos com a perspectiva de que o currículo de Ciências dos três anos iniciais do EF é influenciado por assertivas e tendências difundidas no cenário educacional, sobretudo no contexto de grupos disciplinares de Ciências e, especialmente, de grupos formados por docentes que atuam diretamente nesses anos escolares. Sobre esse aspecto, é pertinente salientar que os professores aptos a atuarem nos anos iniciais são polivalentes ${ }^{5}$. Isto é, profissionais que trabalham conhecimentos de diferentes campos disciplinares. Eque, portanto, a priori, não possuem em sua trajetória formativa uma forte relação com as tradições da disciplina Ciências.

Em contrapartida, aspectos específicos dos referidos anos escolares, como o processo de alfabetização e letramento, e as finalidades compartilhadas em instituições vinculadas à universidade, produzem historicamente uma forma particular de currículo escolar, que valoriza determinadas disposições, sensibilidades e modos de raciocínio, constituindo o currículo como uma forma de regulação social (POPKEWITZ, 2011).

Nesse sentido, apoiando-nos em Popkewitz (2011, 2014), atribuímos ao currículo o poder de regular os indivíduos, possuindo função normatizadora. Isto é, os conhecimentos que ocupam espaço no currículo, concomitantemente com práticas docentes e concepções pedagógicas vinculadas a eles, constituem uma norma ou razão que tem como finalidade a regulação social, formando pessoas "razoáveis".

Ademais, nosso interesse em realizar uma investigação curricular que explore materialidades consiste, principalmente, na possibilidade de acessar a cultura e a forma escolar. Portanto, também dialogamos com referenciais teóricos da cultura material escolar, a fim de projetar luz sobre elementos da cultura escolar. Nesse aspecto, estudos desenvolvidos por Diana Vidal (2005) e Escolano Benito (2010, 2017) subsidiam a análise que propomos.

\footnotetext{
${ }^{5}$ São docentes formados em nível superior, em curso de Pedagogia, ou com formação em nível médio, na modalidade normal. Disponível em: http://www.planalto.gov.br/ccivil 03/_Ato20152018/2017/Lei/L13415.htm\#art7. Acesso em: 21 jun. 2020.
} 
Apropriando-nos da perspectiva de Diana Vidal (2005), entendemos que os objetos e materialidades, quando analisados em produções educacionais, devem ser compreendidos juntamente com diferentes formas de socialização, ou seja, na interação do sujeito com os objetos culturais. Nesse sentido, é notório que os usos dos objetos não são apenas registros documentais do passado, reduzidos às motivações a priori de sua produção. Mas, por outro lado, trazem indícios das subversões cotidianas a esses recursos.

Nesse enfoque, a análise de objetos escolares configura um modo de acessar a experiência e a cultura que se constrói no ambiente escolar. Esse modo de análise permite que as investigações realizadas sob sua perspectiva se atentem ao estudo da ação, entendida como fonte de toda construção cultural. Assim, os objetos escolares carregam consigo certos testemunhos do processo de escolarização, impregnados de signos e sinais, códigos de comunicação e sentidos acordados no processo de escolarização (BENITO, 2010; 2017).

\subsection{Livros de literatura infantil e cultura material escolar}

Deste modo, com base nas elaborações teóricas supracitadas, percebemos os livros de literatura como objetos escolares que permitem o entendimento do conjunto de fazeres ativados no interior da escola, carregando sinais e marcas das práticas escolares, quando observadas em sua regularidade. Eles, também, permitem notar os "vestígios de como os usuários lidavam inventivamente com a profusão material da escola e das mudanças, às vezes imperceptíveis, que impetraram nessas mesmas práticas escolares" (VIDAL, 2005, p. 17). Embora os textos literários não possuam necessariamente finalidades pedagógicas, aqui analisamos apenas livros de literatura infantil que têm seus usos articulados à promoção ou facilitação do trabalho de conhecimentos de Ciências. Isto é, de acordo com as docentes participantes da pesquisa, os livros são usados com fins pedagógicos e didáticos.

No tocante ao contexto escolar dos anos iniciais, Lajolo e Zilberman (2007) indicam que a produção de livros de literatura infantil é orientada a um consumo muito específico, validado e viabilizado por instituições sociais como a escola. Discorrendo sobre a história da literatura infantil, as autoras afirmam que a relação entre a literatura e a escola consiste principalmente na habilitação da criança para o consumo de livros, relacionando-se fortemente com a capacidade de leitura da criança. Assim, a experiência com a literatura infantil

depende também da escolarização da criança, e isso a coloca numa posição subsidiária em relação à educação. Por consequência, adota postura às vezes nitidamente pedagógica, a fim de, se necessário, tornar patente sua utilidade. (LAJOLO; ZILBERMAN, 2007, p. 17-18) 
Nesse cenário, reconhece-se que fatores externos fazem parte da história da literatura infantil, interferindo, inclusive, nos processos de elaboração e na qualidade artística dos textos. Entretanto, essas exigências diversas pelas quais a literatura infantil se esforça em superar, e que, em certa medida, as sujeitam de várias maneiras, circunscrevem a identidade e trajetória desse gênero (LAJOLO; ZILBERMAN, 2007). Portanto, dada a importância dos livros de literatura como objetos historicamente imbricados com a escola, principalmente no processo de alfabetização e letramento, é perceptível como essas materialidades são estabelecidas nas práticas pedagógicas no contexto dos três primeiros anos do EF.

Para a realização desta análise, temos incorporado um outro olhar sobre dados construídos na pesquisa de Queiroz (2019) que, inspirada em Moraes (2015) ${ }^{6}$, teve como estratégia metodológica a realização de entrevistas com quatro professoras atuantes em um dos três primeiros anos do EF, no âmbito do CAp/UFRJ e do Coluni/UFF, e análise de materiais didáticos utilizados em aulas de Ciências, selecionados pelas docentes para o momento da entrevista.

Dentre os objetos selecionados pelas professoras, apareceram dez livros de literatura infantil $^{7}$. Contudo, neste texto, tratamos apenas de duas obras: Diário de Uma Minhoca, de Doreen Cronin e Cocô de Passarinho, de Eva Furnari. Assim, retornamos às transcrições das entrevistas a fim de focalizar os usos dos livros literários e, também, exploramos as materialidades citadas.

\section{Práticas e sentidos dos usos de livros de literatura no currículo de Ciências}

Inicialmente, tratamos do livro Diário de uma Minhoca, cuja autora é Doreen Cronin e o ilustrador, Harry Bliss. O livro foi escrito em 2003 e traduzido por Eduardo Brandão em 2004. A história trata de acontecimentos registrados no diário de uma minhoca "criança". Como mostra a figura 1, em muitos aspectos, essa "pequena" minhoca se aproxima das vivências dos seres humanos: vai à escola, estuda e faz lições de casa, convive em família e amigos. Nessas interações, a minhoca e os animais que aparecem no livro falam e agem como se fossem seres humanos. Deste modo, é notório que o livro tem uma característica antropomórfica, geralmente presente em livros de literatura infantil com seres vivos e fenômenos da natureza como personagens, como salientado por Lopes e Salomão (2007).

\footnotetext{
${ }^{6}$ Bianca Moraes (2017) aponta a potência de conferir poder de seleção aos professores, solicitando que eles indiquem os materiais utilizados em suas práticas docentes, a serem analisados em pesquisas que tratam de currículo e materiais didáticos. Na visão da autora, essa estratégia permite compreender o que vem sendo entendido como recurso didático e quais conhecimentos se integram à disciplina estudada.

${ }^{7}$ Os livros são: Abecedário de Bichos Brasileiros, de Geraldo Valério; No Imenso Mar Azul, de Ana Maria Machado e Claudius; Coisas pra Fazer Antes de Crescer e Cenas da Infância, de James Misse; A Bolsa Amarela, de Lygia Bojunga; Diário de Uma Minhoca, de Doreen Cronin; A Minhoca, de Mônica de Souza e Adriana Ramos; O Dilema do Bicho-Pau, de Angelo Machado; Cocô de Passarinho, de Eva Furnari; e Doce água doce, de Regina Rennó. Todos os livros foram citados por, pelo menos, uma das quatro docentes participantes da pesquisa de Queiroz (2019).
} 
DOI: https://doi.org/10.46667/renbio.v13i1.306

Figura 1: Registros do diário da minhoca.

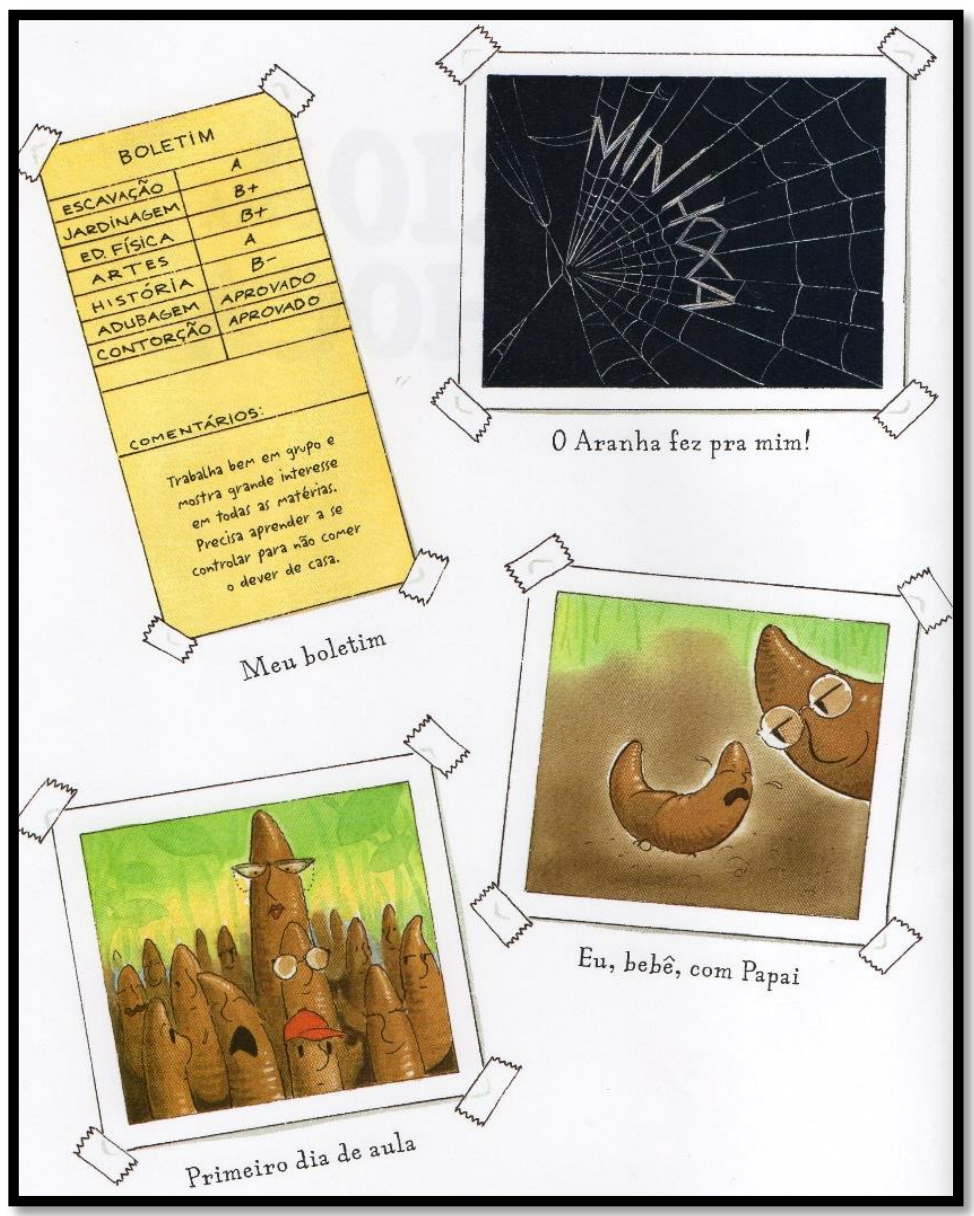

Fonte: Livro “Diário de uma minhoca”, de Doreen Cronin (2004).

Contudo, embora o antropomorfismo esteja presente, as situações registradas no diário da minhoca "criança" fornecem informações características desse ser vivo. Abaixo alguns exemplos:

Mamãe disse que eu sempre devo me lembrar de três coisas:

1. A Terra nos dá tudo que necessitamos.

2. Quando cavamos túneis, ajudamos a cuidar da Terra.

3. Nunca devo chatear Papai quando ele estiver comendo seu jornal.

[...]

10 de abril

Choveu a noite toda e o solo ficou encharcado. Passamos o dia no quintal.

Amarelinha é uma brincadeira perigosíssima.

$[\ldots]$

8 de maio

Tive um pesadelo horrível esta noite... sonhei que umas aves gigantescas brincavam de amarelinha.

Mamãe disse que preciso parar de comer tanto lixo antes de dormir.

(CRONIN, 2004, grifos nossos). 
DOI: https://doi.org/10.46667/renbio.v13i1.306

Assim, as práticas articuladas ao uso desse material, como relata uma das docentes entrevistadas $^{8}$, tiveram início com a curiosidade das crianças sobre o que há debaixo da terra, resultando, então, na elaboração de um minhocário. De acordo com a professora, foi solicitado às crianças observar e registrar informações sobre o minhocário. Nesse processo, textos sobre as minhocas foram introduzidos para que os registros escritos pelos alunos fossem comparados com outros tipos de linguagem. Assim, a docente apresentou textos com linguagem científica, de sites específicos - como o Ciência Hoje para Crianças - e outro livro de literatura - A Minhoca.

Contudo, tendo como inspiração o Diário de uma Minhoca, os registros das crianças constituíram um diário das minhocas. A partir dessa proposta, os alunos notaram características comuns às trabalhadas no livro, como a construção de túneis, exemplificado na Figura 2. Outros aspectos notados também se relacionavam às abordagens das diferentes materialidades mobilizadas pela professora.

Figura 2: Minhoca cavando túnel.

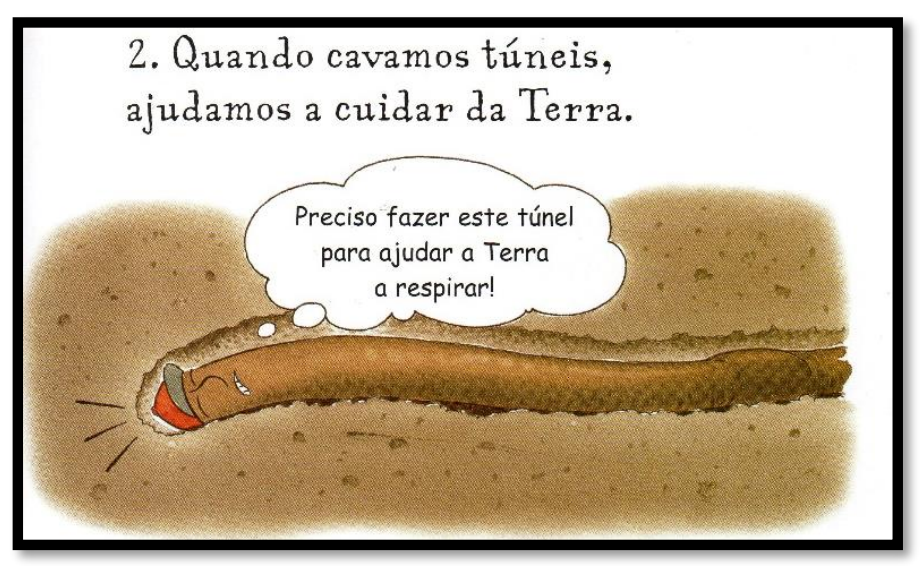

Fonte: Livro “Diário de uma minhoca”, de Doreen Cronin (2004).

Na perspectiva da docente, a atividade configurou uma sequência com início, meio e fim, que despertou grande interesse nos estudantes. Todo processo, desde os materiais utilizados e a forma de produção do minhocário, até as observações morfológicas e do habitat das minhocas, foi registrado pelas crianças.

Nesse enfoque, ressaltamos a importância atribuída à comparação dos diferentes tipos de linguagem em textos que tratam desse animal. Essa prática, imbuída de um forte caráter pedagógico, incide sobre os distintos objetivos dos textos e, segundo a professora, os discentes puderam perceber suas particularidades:

\footnotetext{
${ }^{8}$ Como informado anteriormente, para a escrita deste texto foram analisadas transcrições de entrevistas realizadas com quatro docentes de colégios universitários do Rio de Janeiro. Para o trabalho em questão, recortamos apenas informações referentes às práticas articuladas ao uso de livros de literatura infantil com fins pedagógicos, em aulas de Ciências. Ver mais em Queiroz (2019).
} 
DOI: https://doi.org/10.46667/renbio.v13i1.306

[...] eles [alunos] iam comparando com as informações que já tinham pesquisado e começavam a dizer: "tem livro que conta as coisas, mas não é verdade, a gente já viu que não tem nada a ver com cientista". Eu falei: "é? Por que será?" [os alunos responderam:] "Porque é um livro de histórias" [...] Então eles comparavam: "Realmente tem esses túneis, é verdade. É por onde elas caminham, respiram." (Professora X, grifo nosso) ${ }^{9}$.

Sendo assim, mesmo se valendo de um livro de literatura infantil em aulas de Ciências, esse objeto não é significado como portador de conhecimentos de Ciências que ocupam espaço no currículo escolar. Em contraponto, as características de um texto literário infantil são percebidas e sinalizadas, inclusive, pelas crianças. Por outro lado, no contexto particular dos três primeiros anos do EF, essa materialidade parece atender a finalidades pedagógicas próprias dessa etapa escolar, como o favorecimento do contato com livros de literatura e práticas de leitura e escrita.

O livro Cocô de Passarinho foi escrito e ilustrado por Eva Furnari, e sua primeira edição foi lançada em 1998. Sua história trata de seis habitantes de uma pequena cidade que, todo fim de tarde, se sentavam embaixo de uma árvore para conversar. Como ilustrado na Figura 3, nessa árvore, existiam passarinhos que também pousavam sempre nos mesmos galhos e piavam sempre uns para os outros, como uma forma de "conversar".

Figura 3: Habitantes sob árvore.

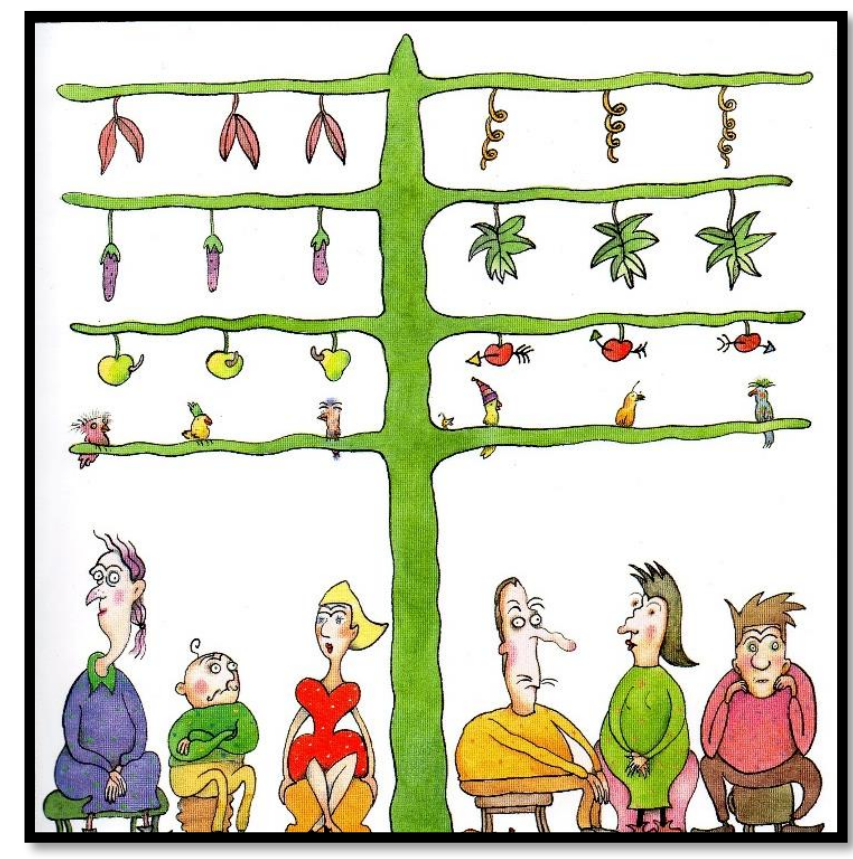

Fonte: Livro “Cocô de Passarinho”, de Eva Furnari (2013).

\footnotetext{
${ }^{9}$ Foi mantida a palavra caminham para ser fiel à transcrição. Mas, de acordo com o contexto, o termo adequado seria rastejam. 
Esses passarinhos sempre faziam cocô na cabeça dos seis moradores, o que os levou a usar chapéus. Certo dia, um vendedor de flores e sementes passou pela cidade e, num momento em que ele se distraiu, os passarinhos comeram algumas sementes. Na semana seguinte, os moradores observaram que seus chapéus estavam "brotando". E, poucos meses depois, os pés cresceram e alguns tinham até ninhos e filhotes.

Deste modo, a história do livro trata de um tema relacionado à dispersão de frutos e sementes por animais, isto é, sobre zoocoria, que é bastante estudado e valorizado na biologia. Especificamente, os pássaros da história ingerem frutos e liberam a semente (Figura 4), se aproximando do conceito de ornitocoria, que é a dispersão de sementes por aves. Embora esse livro de literatura tenha animais como personagens, não observamos forte presença de antropomorfismo, mas notamos a intenção de sugerir uma semelhança entre o encontro cotidiano dos moradores para conversar e o os "passarinhos da praça [que] também pousavam sempre nos mesmos galhos e piavam sempre as mesmas coisas" (FURNARI, 2013, p. 6).

Figura 4: Cocô dos pássaros.

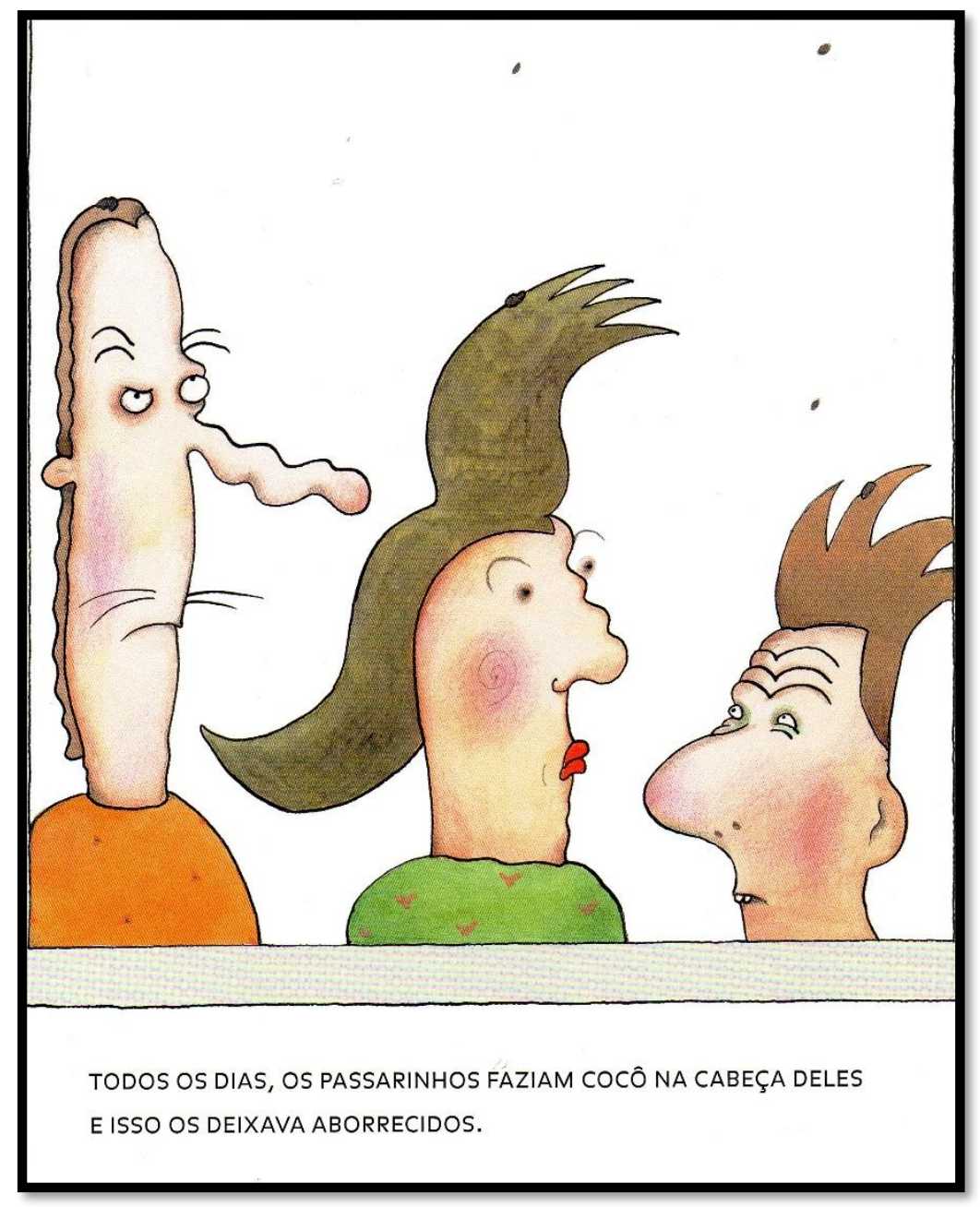

Fonte: Livro "Cocô de Passarinho", de Eva Furnari (2013). 
Portanto, é com a finalidade de abordar a dispersão das sementes que uma das professoras entrevistadas utiliza esse material. Inicialmente, a docente propõe a leitura e interpretação do texto. E, a partir da história, as crianças, juntamente com a professora, fazem observações sobre a leitura:

[...] e eles começavam a dizer: "então nasceu uma plantinha no chapéu de cada um porque foi o passarinho que fez o cocô". E, através da história, eles começavam a observar: "ué, mas o passarinho espalha a semente pela natureza quando come a fruta?!" Sim. E, observando, eles começavam a ver. "É por isso que nasce plantinha no telhado e nunca ninguém plantou" (Professora X).

Nesse aspecto, conhecimentos sobre as formas de dispersão das sementes foram observadas a partir do livro Cocô de Passarinho. No entanto, a docente tem participação ativa na mediação entre o texto apresentado pelo livro e a interpretação e construção de conhecimento pelos alunos. Concomitantemente ao uso do livro, houve a introdução de textos e pesquisas sobre sementes e frutos. Essas práticas permitiram que conhecimentos tradicionalmente biológicos fossem trabalhados.

Assim, é possível notar a valorização do uso de livros de literatura infantil nos três primeiros anos do EF. No tocante à construção do currículo escolar (GOODSON, 1997; 2013), é perceptível que discursos relacionados à ampliação de conhecimentos acerca de gêneros textuais, somado às demandas de alfabetização e letramento, asseguram lugar aos livros de literatura nas práticas dos primeiros anos do EF. A adoção desses objetos é facilitada pelo fato de que alguns livros tratam de temáticas que fazem parte do currículo escolar ou são facilmente adaptáveis.

Como indicado por Lajolo e Zilberman (2007), a literatura infantil tem sua história ligada ao campo educacional e, nas aulas de Ciências, o uso desse recurso tem sido marcado por finalidades pedagógicas, sobretudo no que tange ao processo de alfabetização. Concomitante à facilitação desse processo, embora não seja necessariamente sua principal finalidade, os livros literários infantis carregam certos conhecimentos que fazem parte do currículo escolar de Ciências, o que os torna um recurso que atende a diferentes fins característicos desses anos escolares.

Nesse aspecto, considerando os vestígios que tais recursos fornecem quando compreendidos como objetos escolares (BENITO, 2010; 2012; VIDAL, 2005), os livros de literatura infantil, quando adotados por professoras em aulas de Ciências, incorporam intenções e finalidades pedagógicas. Assim, as motivações de sua produção são forjadas para que esses objetos atendam a demandas escolares. Todavia, a mediação docente entre o texto literário e os conhecimentos curriculares e finalidades pedagógicas está presente em cada etapa das atividades propostas pela professora. 
DOI: https://doi.org/10.46667/renbio.v13i1.306

\section{Conclusões}

Propomos a análise de livros de literatura infantil utilizados com fins didáticos em aulas de Ciências, e práticas pedagógicas articuladas a eles, para compreender quais normas e padrões regulam o currículo de Ciências nos três anos iniciais do EF. Nosso arcabouço teórico é composto pelas assertivas de Ivor Goodson (1997, 2013) e Thomas Popkewitz (2011, 2014), que nos orientam a desnaturalizar o currículo escolar, e concebê-lo como um artefato construído social e historicamente, produzindo modos de ser, pensar e agir, isto é, sistemas de razão que regulam os sujeitos. Com relação aos livros de literatura infantil utilizados com fins didáticos, entendemos que essas materialidades se constituem em objetos escolares que carregam sinais da escolarização e dos discursos que regem a cultura escolar (BENITO, 2010; 2017).

Concluindo, nossas análises indicam que os livros de literatura incorporam finalidades pedagógicas em aulas de Ciências. Os usos de tais objetos escolares se articulam, principalmente, com o ensino de conhecimentos que ocupam espaço no currículo escolar de Ciências, incorporando finalidades pedagógicas e escolares. No entanto, é a prática docente que promove a articulação entre os textos literários e o currículo de Ciências. Observa-se que nas práticas escolares o texto literário é questionado, posto em xeque ou complementado com outro recurso. Essas abordagens fornecem indícios de que esse recurso não é concebido como contendo conhecimentos disciplinares tradicionais ou "verdadeiros". Assim, ora a leitura do livro é utilizada para completar e concluir atividades já em andamento a partir de outros recursos pedagógicos, ora é utilizada como o início de busca de informações e conhecimentos acerca de aspectos do mundo natural. Em ambas as situações os livros de literatura infantil se configuram como importantes recursos didáticos para as aulas de Ciências. 
DOI: https://doi.org/10.46667/renbio.v13i1.306

\section{Referências}

BENITO, A. E. A escola como cultura: experiência, memória e arqueologia. Campinas, SP: Alínea Editora, 2017.

BENITO, A. E. Patrimonio material de la escuela e historia cultural. Revista Linhas, v. 11, n. 02, p. 13-28, jul./dez. 2010.

CRONIN, D. Diário de uma minhoca. São Paulo, SP: Companhia das Letrinhas, 2004.

FURNARI, E. Cocô de passarinho. São Paulo, SP: Moderna, 2013.

GOODSON, I. F. A construção social do currículo. Lisboa: Educa, 1997.

GOODSON, I. F. Currículo: teoria e história. Petrópolis, RJ: Vozes, 2013.

LAJOLO, M.; ZILBERMAN, R. Literatura infantil brasileira: história \& histórias. São Paulo, SP: Ática, 2007.

LOPES, E. M.; SALOMÃO, S. R. O uso da literatura no ensino de Ciências no primeiro segmento do ensino fundamental: desafios e possibilidades. In: ENCONTRO NACIONAL DE PESQUISA EM EDUCAÇÃO EM CIÊNCIAS, 7., Florianópolis, 2009.

Anais...Florianópolis: UFSC, 2009.

MORAES, B. G. S. Materiais didáticos como "inovações" curriculares: entre saberes docentes e "tradições" da disciplina escolar Ciências. 129f. 2015. Dissertação (Mestrado em Educação) - Universidade Federal do Rio de Janeiro. Rio de Janeiro, RJ, 2015.

POPKEWITZ, T. S. História do currículo, regulação social e poder. In: SILVA, T. T. (Org.). O sujeito da educação: estudos foucaultianos. 8.ed. Petrópolis, RJ: Vozes, 2011.

POPKEWITZ, T. S. Social epistemology, the reason of "reason" and the curriculum studies. Education Policy Analysis Archives, v. 22, n. 22, p. 1-23, abr./ 2014. Disponível em: http://dx.doi.org/10.14507/eppopkewitzaa.v22n22. 2014. Acesso em: 20/04/2018.

QUEIROZ, L. S. Currículo de Ciências nos anos iniciais do Ensino Fundamental: materiais didáticos utilizados em colégios universitários do Rio de Janeiro.128f. 2019. Dissertação (Mestrado em Educação) - Universidade Federal do Rio de Janeiro, Rio de Janeiro, RJ, 2019.

VIDAL, D. G. Cultura e prática escolares: uma reflexão sobre documentos e arquivos escolares. In: SOUZA, R. F.; VALDEMARIN, V. T. (Org.). A cultura escolar em debate: questões conceituais, metodológicas e desafios para a pesquisa. Campinas, SP: Autores Associados, 2005. 